\title{
A multidisciplinary approach remains the best strategy to improve and strengthen the management of ovarian cancer (Review)
}

\author{
LUCA FALZONE $^{1 *}$, GIUSEPPA SCANDURRA ${ }^{2 *}$, VALENTINA LOMBARDO $^{2}$, GIUSEPPE GATTUSO $^{3}$, \\ ALESSANDRO LAVORO ${ }^{3}$, ANDREA BENEDETTO DISTEFANO $^{4}$, GIUSEPPE SCIBILIA $^{4}$ and PAOLO SCOLLO ${ }^{4}$ \\ ${ }^{1}$ Epidemiology and Biostatistics Unit, National Cancer Institute-IRCCS Fondazione G. Pascale, I-80131 Naples; \\ ${ }^{2}$ Medical Oncology Unit, Cannizzaro Hospital, I-95126 Catania; ${ }^{3}$ Department of Biomedical and Biotechnological Sciences, \\ University of Catania, I-95123 Catania; ${ }^{4}$ Unit of Obstetrics and Gynecology, Cannizzaro Hospital, I-95126 Catania, Italy
}

Received March 7, 2021; Accepted March 31, 2021

DOI: $10.3892 / \mathrm{ijo} .2021 .5233$

\begin{abstract}
Ovarian cancer represents one of the most aggressive female tumors worldwide. Over the decades, the therapeutic options for the treatment of ovarian cancer have been improved significantly through the advancement of surgical techniques as well as the availability of novel effective drugs able to extend the life expectancy of patients. However, due to its clinical, biological and molecular complexity, ovarian cancer is still considered one of the most difficult tumors to manage. In this context, several studies have highlighted how a multidisciplinary approach to this pathology improves the prognosis and survival of patients with ovarian cancer. On these bases, the aim of the present review is to present recent advantages in the diagnosis, staging and treatment of ovarian cancer highlighting the benefits of a patient-centered care approach and on the importance of a multidisciplinary team for the management of ovarian cancer.
\end{abstract}

\section{Contents}

1. Introduction

2. Risk and protective factors for ovarian cancer

3. Ovarian cancer symptoms, diagnosis and staging

4. Ovarian cancer surgical treatments

5. Ovarian cancer pharmacological treatments

6. Ovarian cancer management: From linear to multidisciplinary patient-centered care approach

7. Conclusions

Correspondence to: Dr Luca Falzone, Epidemiology and Biostatistics Unit, National Cancer Institute-IRCCS Fondazione G. Pascale, Via Mariano Semmola 53, I-80131 Naples, Italy

E-mail: 1.falzone@istitutotumori.na.it

${ }^{*}$ Contributed equally

Key words: ovarian cancer, patient-centered care, multidisciplinary team, multidisciplinary approach, poly (ADP-ribose) polymerase inhibitors, diagnosis, staging, therapy

\section{Introduction}

Ovarian cancer represents the eighth most frequently diagnosed tumor and the seventh most lethal cancer in women leading to almost 185,000 deaths annually worldwide (1). Despite the improvement of screening strategies and the advancement of anticancer surgical and pharmacological treatments, ovarian cancer is still considered one of the most commonly diagnosed and aggressive urogenital female tumors, with a 5-year relative survival rate of $93 \%$ and 5-year cause-specific survival rates of 82, 71, 66 and $43 \%$ for endometrioid, mucinous, clear cell carcinoma and serous ovary carcinoma, respectively $(2,3)$. The majority of ovarian cancer cases are epithelial, which accounts for $85-90 \%$ of all diagnosed ovarian tumors. This type of tumor usually affects women aged between 55 and 65 years old (4); contrariwise, germ cell ovarian cancer accounts for $\sim 5 \%$ of all diagnosed tumors with an average age of onset of 20 years old (4).

\section{Risk and protective factors for ovarian cancer}

Several risk factors have been recognized for ovarian cancer. It was demonstrated that the risk of developing ovarian cancer increases significantly with age and in particular after menopause, probably due to hormonal imbalance (5). In this regard, it was observed that post-menopause hormone therapies, based on the administration of estrogens alone or in combination with progesterone, significantly increased the risk of developing ovarian cancer (relative risk, 1.53; confidence interval, 1.40-1.66) (6). Strictly associated with menopause and hormone imbalance risk factors, weight gain and obesity have also been associated with an increased risk of ovarian cancer (7). Of note, obesity represents one of the main important modifiable risk factors for different tumors. In patients suffering from ovarian cancer, it was also demonstrated that obesity negatively affects the prognosis of patients leading to therapeutic failure and worse overall survival time (7). As widely described for other tumors such as breast and prostate cancer $(8,9)$, besides these physiological variations of hormone levels, occupational and environmental risk factors as well as endocrine disruptors and other chemical substances have been associated with the development of ovarian cancer (10-13). 
Other well-recognized risk factors are gene mutations and hereditary syndromes that represent the most notable predisposing causes for the development of ovarian cancer (14). A growing body of literature has demonstrated that individuals harboring germline mutations affecting $B R C A 1$ and $B R C A 2$ genes have an increased risk of breast and ovarian cancer (15-18). Overall, $25 \%$ of ovarian cancer tumors are positive for BRCA1 or BRCA2 mutations (19). As explained in the following sections, the evaluation of such mutations is important for the choice of anticancer pharmacological treatments $(20,21)$. Other hereditary syndromes related to ovarian cancer include hereditary non-polyposis colon cancer syndrome, Peutz-Jeghers syndrome and adenine DNA glycosylase (MUTYH)-associated polyposis syndrome affecting several mismatch repair genes (including $\mathrm{MSH}$, $\mathrm{MSH} 6$ and MLH1), STK11 and MUTYH (22-24), respectively.

Other controversial and not yet ascertained risk factors are represented by tobacco smoking, androgens, diet and talc powder. For all these risk factors, observational, case-control, retro- and prospective studies have generated conflicting results thus limiting the awareness about the causative effects of these factors (25). It was demonstrated that tobacco smoking is associated with the development of mucinous ovarian cancer, but it does not increase susceptibility to other types of ovarian tumors $(26,27)$. Unconvincing data have been obtained for the association between powder use in the genital area and the risk of ovarian cancer. In this context, some studies highlighted a slightly increased risk of ovarian cancer in women using talc powder in the genital area (28-30). However, a recent observational study on 250,000 women observed for 11 years has demonstrated that the use of powder does not significantly increase the incidence of ovarian cancer (28-30).

Besides these risk factors, numerous studies have also identified some protective factors able to reduce the incidence of ovarian cancer. Among these factors, pregnancy and breastfeeding are both associated with a reduced risk of developing this tumor. In particular, a significantly reduced risk for ovarian cancer has been observed in women carrying full-term pregnancies before 26 years old (31). In addition, the increased number of full-term pregnancies, together with the time of breastfeeding, is associated with a lower risk of ovarian cancer (31). Finally, the use of oral contraceptives for birth control seems to play an important protective role against ovarian cancer with higher protective effects the longer the treatments are administered (32). In this context, other birth control strategies, including intrauterine devices and tubal ligation, have also been associated with a reduced risk of ovarian cancer (33).

\section{Ovarian cancer symptoms, diagnosis and staging}

During the early stages, ovarian cancer is not associated with clinical symptoms, therefore the diagnosis of this tumor is often delayed. Mild ovarian cancer symptoms may be often confused with other benign pathologies, including gastrointestinal disorders, urogenital infections and benign ovarian lesions (including ovarian cysts, teratomas and fibromas) (34). However, unlike benign diseases, ovarian cancer symptoms are persistent and worsen over time (34). Generally, moderate or severe symptoms are associated with the spread of the disease in adjacent anatomical regions. Among these symptoms, the most frequently observed are pelvic distension, abdominal and pelvic pain and urgent or frequent urination (34). Other symptoms may include pain during sex, back pain, constipation, altered menstruation, fatigue and weight loss (35). The correct self-assessment of these symptoms by the patients may improve the timing of diagnosis allowing the gynecological surgeon and oncologist to intervene promptly by increasing the patient response to treatments (36).

Regarding ovarian cancer staging, two main staging systems are used worldwide for ovarian cancer, which are the International Federation of Gynecology and Obstetrics (FIGO 2018) system and the American Joint Committee on Cancer (AJCC 8th edition) system both based on the Tumor-Node-Metastasis (TNM) parameters $(37,38)$. Table I shows both FIGO and AJCC staging in terms of the pathological characteristics of tumors: Tumor dimension (T), lymph node involvement $(\mathrm{N})$ and presence of distant metastasis (M) (Table I).

At present, several diagnostic strategies are available to make a correct and timely diagnosis of ovarian cancer when recurrent symptoms are observed. The first step for a correct diagnosis of ovarian cancer is based on the collection of patient's medical history and on a correct physical exam performed by a gynecologist with expertise in gynecological oncology $(39,40)$. The aim of these procedures is the collection of all relevant data about the presence of pre-existing conditions or risk factors that could increase the risk of developing ovarian cancer. In particular, as previously mentioned, the presence of a family member with ovarian cancer or the presence of hereditary syndromes and genetic mutations may lead the clinician to make a diagnosis of suspected ovarian cancer in the presence of specific abdominal symptoms. In the same manner, the physical examination of the abdomen and pelvis is of fundamental importance to observe pelvic mass, ascites or abdominal distension suggestive of ovarian cancer (41). The physical examination could include a rectovaginal exam performed with empty bladder to evaluate the presence of abdominal or pelvic masses. However, although important and easy to perform, physical investigations have a low sensitivity and a low specificity, especially in overweight patients or in presence of small tumors, as abdominal or pelvic distention may be caused by other benign pathologies $(42,43)$.

After the physical examination, patients with suspected ovarian cancer are subjected to various laboratory and imaging tests useful to detect the presence of the tumor, its severity and extent (41). Among the most used laboratory tests both for preventive and diagnostic purposes is the evaluation of blood tumor markers, namely cancer antigen (CA) 125 and human epididymis protein 4 (HE4), alongside the normal hematochemical parameters (red and white blood cells count, platelets and hemoglobin). In particular, CA 125 is considered the main predictive serum biomarker for ovarian cancer as it is elevated in $50 \%$ of patients with early-stage ovarian cancer and in over $80 \%$ of all patients with this tumor (44).

Regarding HE4, this marker is evaluated together with CA 125 as it appears to be elevated in a significant fraction of patients with ovarian cancer negative for CA $125(45,46)$. Therefore, the use of HE4 is of fundamental importance in screening strategies to intercept all those ovarian carcinomas negative for other tumor biomarkers. The evaluation of these 
Table I. Ovarian cancer staging and pathological features.

\begin{tabular}{|c|c|c|c|}
\hline $\begin{array}{l}\text { FIGO } \\
\text { stage }\end{array}$ & $\begin{array}{l}\text { AJCC } \\
\text { stage }\end{array}$ & $\begin{array}{c}\text { TNM } \\
\text { characteristics }\end{array}$ & Description of tumor \\
\hline I & I & $\begin{array}{l}\text { T1 } \\
\text { N0 } \\
\text { M0 }\end{array}$ & $\begin{array}{l}\text { The tumor is limited to the inner part of one ovary (T1) and there is no involvement of } \\
\text { neighboring lymph nodes (N0). There are no metastases (M0). }\end{array}$ \\
\hline IA & IA & $\begin{array}{l}\text { T1a } \\
\text { N0 } \\
\text { M0 }\end{array}$ & $\begin{array}{l}\text { The tumor is limited to the inner part of one ovary without the involvement of } \\
\text { the outer surface (T1a) and there is no involvement of neighboring } \\
\text { lymph nodes (N0). There are no metastases (M0). }\end{array}$ \\
\hline IB & IB & $\begin{array}{l}\text { T1b } \\
\text { N0 } \\
\text { M0 }\end{array}$ & $\begin{array}{l}\text { The tumor is limited to the inner part of both ovaries and there are no cancer cells in ascites } \\
\text { or in the abdominal and pelvic cavities (T1b) and there is no involvement of } \\
\text { neighboring lymph nodes (N0). There are no metastases (M0). }\end{array}$ \\
\hline IC & $\mathrm{IC}$ & $\begin{array}{l}\text { T1c } \\
\text { N0 } \\
\text { M0 }\end{array}$ & $\begin{array}{l}\text { The tumor is in one or both ovaries and the tumor capsule is broken during surgery (IC1); } \\
\text { the tumor capsule is broken before surgery or the tumor is on the outer surface of } \\
\text { the ovary(ies) (IC2); tumor cells are present in the ascitic fluid or in the washing liquid } \\
\text { obtained from the abdomen and pelvis (IC3). There is no involvement } \\
\text { of neighboring lymph nodes (N0). There are no metastases (M0). }\end{array}$ \\
\hline II & II & $\begin{array}{l}\text { T2 } \\
\text { N0 } \\
\text { M0 }\end{array}$ & $\begin{array}{l}\text { The tumor is in one or both ovaries and has spread to other adjacent pelvic organs or } \\
\text { to the peritoneum (T2). There is no involvement of neighboring } \\
\text { lymph nodes (N0). There are no metastases (M0). }\end{array}$ \\
\hline IIA & IIA & $\begin{array}{l}\text { T2a } \\
\text { N0 } \\
\text { M0 }\end{array}$ & $\begin{array}{l}\text { The tumor has invaded or grown into the uterus or the fallopian tubes (T2a). } \\
\text { It has not invaded lymph nodes (N0) or distant sites (M0). }\end{array}$ \\
\hline IIB & IIB & $\begin{array}{l}\text { T2b } \\
\text { N0 } \\
\text { M0 }\end{array}$ & $\begin{array}{l}\text { The tumor has invaded the outer and inner surface of pelvic organs including, uterus, } \\
\text { fallopian tubes, bladder and sigmoid colon (T2b). There is no involvement of neighboring } \\
\text { lymph nodes (N0). There are no metastases (M0). }\end{array}$ \\
\hline IIIA1 & IIIA1 & $\begin{array}{l}\text { T1-2 } \\
\text { N1 } \\
\text { M0 }\end{array}$ & $\begin{array}{l}\text { The tumor has invaded ovaries, the peritoneum and other pelvic organs (T1-2). } \\
\text { The tumor has spread to the retroperitoneal (pelvic and/or para-aortic) } \\
\text { lymph nodes (N1) without forming distant metastasis (M0). }\end{array}$ \\
\hline IIIA2 & IIIA2 & $\begin{array}{l}\text { T3a } \\
\text { N0-1 } \\
\text { M0 }\end{array}$ & $\begin{array}{l}\text { The tumor affects one or both ovaries and has invaded the peritoneal cavity } \\
\text { and organs outside the pelvis; however, it is not visible during } \\
\text { surgery (T3a). The tumor is present or not on the retroperitoneal } \\
\text { lymph nodes (N0-1). There are no metastases (M0). }\end{array}$ \\
\hline IIIB & IIIB & $\begin{array}{l}\text { T3b } \\
\text { N0-1 } \\
\text { M0 }\end{array}$ & $\begin{array}{l}\text { The tumor affects one or both ovaries and has invaded the peritoneal cavity and organs outside } \\
\text { the pelvis. During surgery the tumor is visible but is }<2 \mathrm{~cm}(\mathrm{~T} 3 \mathrm{~b}) \text {. The tumor is present or not } \\
\text { on the retroperitoneal lymph nodes (N0-1). There are no metastases (M0). }\end{array}$ \\
\hline IIIC & IIIC & $\begin{array}{l}\text { T3c } \\
\text { N0-1 } \\
\text { M0 }\end{array}$ & $\begin{array}{l}\text { The tumor affects one or both ovaries and has invaded the peritoneal cavity and organs outside } \\
\text { the pelvis. During surgery the tumor is visible and is }>2 \mathrm{~cm} \text { (T3c). The tumor is present or not } \\
\text { on retroperitoneal lymph nodes (N0-1). There are no metastases (M0). }\end{array}$ \\
\hline IVA & IVA & $\begin{array}{l}\text { T1-4 } \\
\text { N0-3 } \\
\text { M1a }\end{array}$ & $\begin{array}{l}\text { The tumor is present or not on retroperitoneal lymph nodes (N0-3). Tumor cells have invaded } \\
\text { the bloodstream leading to malignant pleural effusion. However, cancer cells have not invaded } \\
\text { the spleen, intestine, liver neither lymph nodes outside the abdominal cavity (M1a). }\end{array}$ \\
\hline IVB & IVB & $\begin{array}{l}\text { T1-4 } \\
\text { N0-3 } \\
\text { M1b }\end{array}$ & $\begin{array}{l}\text { The tumor is present or not on retroperitoneal lymph nodes (N0-3). } \\
\text { The tumor has spread to the liver or spleen, to extra abdominal lymph nodes } \\
\text { and/or to other extra peritoneal organs or tissues, such as the lungs and bones (M1b). }\end{array}$ \\
\hline
\end{tabular}

FIGO, International Federation of Gynecology and Obstetrics; AJCC, American Joint Committee on Cancer; T, tumor; N, node; M, metastasis.

two markers, together with the evaluation of six symptoms predicting the presence of ovarian cancer (pelvic pain, abdominal pain, urinary urgency/frequency, increased abdominal size, bloating and difficulty eating/feeling full) showed a significant improvement in diagnostic accuracy from 83.8 to $98.5 \%$ (46). Other tumor biomarkers, such as serum $\alpha$-fetoprotein and quantitative $\beta$-human chorionic gonadotropin ( $\beta$-hCG), are less used and are used for the diagnosis of germ cell ovarian cancer (47). 
After these preliminary assessments, women who present symptoms and biomarkers predictive for ovarian cancer undergo imaging tests, including ultrasound, computed tomography (CT) scan, magnetic resonance imaging (MRI) scan and positron emission tomography (PET) scan (48).

Generally, the first imaging test to be performed is a transvaginal ultrasonography. Several studies have shown how transvaginal ultrasonography is able to distinguish benign lesions from tumors with an excellent rate of accuracy (pooled sensitivity and specificity of 92 and $88 \%$, respectively) thus allowing the clinician to evaluate the structure and vascularization of the ovarian parenchyma, the presence of cysts or masses and any ascitic effusions (49-52).

Both CT, MRI and PET are not widely used for the diagnosis of ovarian cancer but for the evaluation of the extent of the tumor and the possible presence of distant metastases. Specifically, CT scan can be used to perform biopsies of suspected metastases in a procedure called CT-guided needle biopsy $(53,54)$. Meanwhile, PET and MRI are mostly used to evaluate the spread of diseases in neighboring lymph node stations and in distant organs, such as the medulla and brain, through the use of radiotracers or contrast agents (for example gadolinium) (55).

Finally, after tumor diagnosis, it is essential to perform molecular tests and genetic counseling to determine the presence of relevant mutations in tumor specimens useful for prognostic and therapeutic purposes (56-60). As aforementioned, the most frequent mutations observed in ovarian cancer are those affecting the $B R C A 1$ and $B R C A 2$ genes as well as other mutations within STK11, MSH2, MSH6, MLH1, PMS6 and MUTYH $(56,57)$. Besides molecular evaluations, previous studies have demonstrated that immunohistochemical investigations are fundamental both for diagnostic and prognostic purposes for different abdominal tumors, including that of ovaries (58-60).

\section{Ovarian cancer surgical treatments}

Over the decades, the therapeutic options for the treatment of advanced ovarian cancer have been improved significantly through the development of more precise and less invasive surgical techniques as well as the availability of novel effective drugs able to extend the life expectancy of patients, especially for metastatic ovarian cancer $(61,62)$. Different studies have demonstrated that in the last 20-35 years there was a significant improvement in the survival rates of patients with ovarian cancer; however, some reports have shown that the advancements of the anticancer treatment have not ameliorated the long-term survival and the cure rate of ovarian cancer (63-65). In particular, a recent study showed that both incidence and 5-year survival rates have improved in the last 30 years. Indeed, the 5-year survival rate increased from $39.3 \%$ in the 80 s to $45.4 \%$ observed in 2012; similarly, the survival time was also improved passing from 34 months observed in 1983 to 52 months observed in 2012, highlighting how the latest treatments have improved the survival time of patients with ovarian cancer (62).

At present, surgery represents the gold standard for the treatment of ovarian cancer. Ovariectomy and adnexectomy are used for both staging, debulking and treatment of early ovarian cancer, thus being curative in such tumors limited to the ovaries $(66,67)$. Ovarian cancer surgery can be performed by open surgery with midline incision or by minimally invasive surgery (MIS). MIS, performed by laparoscopic surgery, is generally performed for newly diagnosed tumors limited to one or both ovaries and to the pelvic cavity without metastatic dissemination (68). However, MIS is generally used only in structured centers equipped with experienced gynecological surgeons (68). In the case of advanced tumors (stages II, III and IV), open surgery is always used in order to perform extended cytoreduction (debulking) aimed at eliminating all cancer lesions with a thickness of $>1 \mathrm{~cm}(69,70)$. Briefly, in both MIS and open surgery, the first steps consist in the collection of ascitic fluid and in the execution of peritoneal lavage used for immunocytochemistry evaluations useful to establish the presence of tumor cells in the peritoneal cavity (71). Subsequently, surgeons check the entire peritoneal cavity to assess the absence of any suspicious extra ovary lesions. In the case of no suspicious masses, biopsies from different parts of the peritoneal cavity (paracolic gutters, pelvis and diaphragm) should be obtained to exclude cancer dissemination (71). After these preliminary steps, surgeons can remove the primary tumor through bilateral salpingo-oophorectomy, hysterectomy, omentectomy and lymph node dissection (both pelvic and paraaortic nodes). To avoid post-surgery cancer dissemination, the tumor has to be removed encapsulated. In the case of young patients (20-45 years old) with monolateral stage IA and IC ovarian cancer that would maintain fertility, the surgeon could opt for unilateral ovariectomy and adnexectomy, thus preserving the contralateral ovary and uterus (71).

Overall, the main objectives of ovarian cancer surgery are the removal of the primary tumor and the maximal debulking of pelvic and peritoneal masses. In presence of advanced tumors, the clinicians can opt for neoadjuvant chemotherapy (NAC) followed by debulking surgery. If the NAC plus surgery approach is chosen, tumor biopsies are collected before chemotherapy to assess the molecular features of the tumors (through immunohistochemistry or molecular tests) thus allowing administration of appropriate anticancer drugs (72). In those patients undergoing NAC and debulking surgery, a whole-abdominal radiation treatment should be applied if residual disease is still observed after a second-look laparotomy; however, this approach needs to be carefully evaluated to avoid bowel toxicity $(73,74)$.

\section{Ovarian cancer pharmacological treatments}

Besides surgery, anticancer pharmacological treatments are the best therapeutic option for the management of ovarian cancer. Over the years, several chemotherapeutic agents have been used for the treatment of ovarian cancer. Thanks to the evolution of anticancer pharmacological treatments, it is now possible to effectively treat the different histological and molecular subtypes of ovarian cancer, contributing to the improvement of the quality of life and life expectancy of these patients $(2,75)$.

Ovarian cancer chemotherapy. After surgery, chemotherapy can be optionally administered in patients with low-grade tumors (stage IA or IB), while the first-line treatment for 

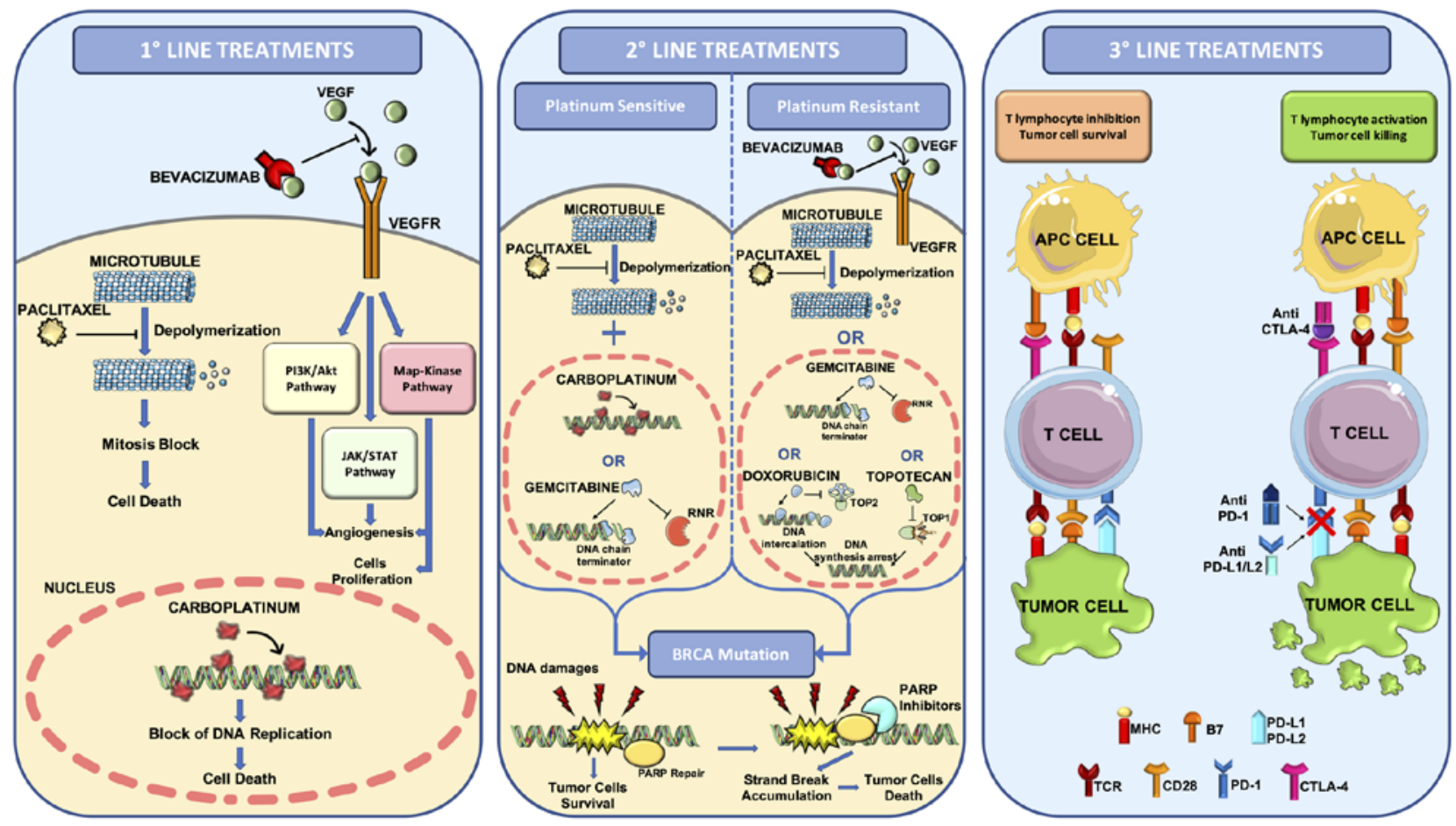

Figure 1. Overview of the pharmacological treatments for the management of ovarian cancer. First-line treatments based on the administration of platinum/taxane regimen plus anti-VEGF mAb bevacizumab. Second-line treatments based on the administration of paclitaxel plus carboplatin or gemcitabine in the case of platinum sensitive tumors or bevacizumab plus paclitaxel, gemcitabine, doxorubicin or topotecan in the case of platinum resistant tumors. For BRCA mutated ovarian cancer, PARP inhibitors can be used for first-line or second-line treatments. Third-line treatments consist in the administration of the first-line and second-line drugs plus immune checkpoint inhibitors. MHC, major histocompatibility complex; RNR, ribonucleotide reductase; TCR, T-cell receptor; TOP1, type 1 topoisomerase; TOP2, type 2 topoisomerase.

ovarian cancer with more advanced stages is based on the administration of platinum-based chemotherapy. Indeed, the first-line regimen consists of the administration of intravenous platinum/taxane every three weeks for six cycles (76). The same compounds are usually administered also in patients with stage III/IV ovarian cancer undergoing NAC protocols for three cycles followed by debulking surgery plus six additional cycles of platinum/taxane (76,77).

Thus, for $>20$ years, the first-line treatment for ovarian cancer has been based on the administration of carboplatin (used instead of cisplatin because it is less toxic and equally effective) and paclitaxel administered every three weeks in a six-cycle schedule. The preferred route of administration is the intravenous systemic one, although several studies have also proposed intraperitoneal administration, which has not given improved results in terms of improvement of progression-free survival (PFS) $(78,79)$. Similarly, several trials have investigated the beneficial effects of paclitaxel weekly administration compared with the conventional 3-week schedule; however, this therapeutic option is not widely used as conflicting data have been generated in three different clinical studies (JGOG 3016, GOG 262 and MITO 7) (80-82) (Fig. 1).

More recently, the introduction of anticancer targeted therapies has improved the efficacy of first-line treatments for patients with ovarian cancer who can benefit from treatments based on the administration of carboplatin, paclitaxel and bevacizumab $(83,84)$. Bevacizumab is a monoclonal antibody against the pro-angiogenetic factor VEGF-A that has prolonged the PFS and OS time of patients, especially of those patients with advanced tumors (83). In particular, it was demonstrated that the prolonged administration of $15 \mathrm{mg} / \mathrm{kg}$ 3-weekly of bevacizumab up to 15 months together with standard carboplatin/paclitaxel chemotherapy is associated with a prolonged PFS time; however, due to the expensive cost of treatments and the related gastrointestinal and vascular toxicities, novel protocols based on a low dose of bevacizumab for 30 months is still under evaluation and it is awaiting approval as a therapeutic standard for this tumor $(76,85,86)$ (Fig. 1).

After the first-line chemo- and targeted therapy, the patients can completely respond to treatments or develop a relapse. In the case of a partial or complete response, patients can undergo maintenance chemotherapy with the same drugs used in the first-line treatment to improve PFS $(87,88)$.

In the case of tumor recurrence, patients are treated with a second-line treatment that is different depending on whether the tumor is resistant or sensitive to platinum compounds $(89,90)$. Tumor recurrence can be observed through biochemical (increased expression of CA125 and other biomarkers) or clinical (imaging techniques) examinations (91) after which patients are assigned to standard treatment for recurrent disease or to experimental clinical trials using novel drugs or different drug combinations $(92,93)$.

For patients with ovarian cancer developing a platinum-resistant disease, the second-line treatments consist of single non-platinum-based therapies using different agents, including docetaxel, paclitaxel, topotecan and gemcitabine, with a therapeutic efficacy ranging from 19 to $27 \%$ of the treated patients (71). Similar percentages of response have been obtained treating ovarian cancer relapse with bevacizumab (therapeutic response observed in $20 \%$ of patients) (94). More 
recently, in absence of severe adverse events, combined therapies with bevacizumab plus one agent among doxorubicin, topotecan and paclitaxel have shown a significant improvement of OS in patients with platinum-resistant recurrent disease (95) (Fig. 1).

In the case of platinum-sensitive recurrence, there are different therapeutic options based on the administration of several drug combinations including carboplatin plus paclitaxel (or docetaxel with weakly or 3-weeks administration), carboplatin plus gemcitabine and bevacizumab, carboplatin plus liposomal doxorubicin and cisplatin plus gemcitabine (96). In addition, patients with ovarian cancer who are platinum-sensitive are often eligible for novel clinical trials assessing the efficacy of novel agents or combined therapies. Among these trials, recent evidence has demonstrated the therapeutic efficacy of poly (ADP-ribose) polymerase (PARP) inhibitors in both platinum-sensitive and -resistant ovarian cancer harboring BRCA1 or BRCA2 mutations. In particular, patients with platinum-sensitivity with complete or partial response to at least two lines of treatments can benefit from olaparib single-agent maintenance therapy improving their PFS from 5.5 to 19.1 months (97). Similarly, olaparib single-therapy can be used also in patients with platinum-resistant $B R C A$ mutated ovarian cancer who failed three or more lines of chemotherapy (98) (Fig. 1).

Novel first-line and second-line treatments with PARP inhibitors. As aforementioned, some patients with ovarian cancer can benefit from novel first-line and second-line treatments based on the administration of selective inhibitors of PARP. PARP proteins are a family of 17 enzymes involved in numerous cellular processes, and in particular PARP-1 and PARP-2 play a crucial role in DNA damage repair $(99,100)$.

The development of PARP inhibitors has represented the turning point in the treatment of ovarian cancer, both in the first-line and in case of tumor recurrence, highlighting the importance of studying the molecular profile of tumors to improve the selection of patients eligible for these innovative treatments. Indeed, these drugs, including olaparib, rucaparib, niraparib and talazoparib, find application in tumors with germline mutations affecting $B R C A 1$ and $B R C A 2$ or in advanced ovarian cancer refractory to three or more lines of treatment (101).

Recent evidence has demonstrated that patients with ovarian cancer harboring $B R C A 1$ or $B R C A 2$ mutations could benefit from a first-line or a second-line treatment with olaparib, which reduces the risk of progression or death by $70 \%$ compared with placebo in patients who achieved a complete or partial response to the first platinum-based line. In particular, $60.4 \%$ of patients treated with olaparib showed a progression-free survival of 36 months compared with $26.9 \%$ of women in the placebo arm (102). These data are further corroborated by the results presented during the European Society for Medical Oncology 2019 and European Society of Gynecological Oncology 2019 conferences regarding two clinical trials using niraparib and olaparib plus bevacizumab (PRIMA and PAOLA 1 trials, respectively) as first-line treatments (103-105). The therapeutic efficacy of PARP inhibitors has been demonstrated mainly in patients with BRCA1/2-positive ovarian cancer who develop platinum-sensitive relapse. In these patients, maintenance treatment with olaparib significantly improves overall survival time (SOLO2 and E19 trials) (106-108).

The therapeutic efficacy of PARP inhibitors has been demonstrated also in patients without BRCA mutations. The NOVA trial based on the administration of niraparib in patients with ovarian cancer demonstrated that all patients can benefit from this treatment, although improved results were obtained for patients with homologous recombination deficiency (HRD) compared with patients without mutations affecting the HR system (105).

In December 2016, the Food and Drug Administration launched an accelerated approval process for the use of rucaparib as a single agent for the treatment of patients with ovarian cancer at an advanced stage and with a BRCA mutation (germline or somatic) who had been previously treated with two or more lines of chemotherapy (109). In addition, rucaparib is also used as second-line maintenance therapy in patients with platinum-sensitivity with or without $B R C A 1 / 2$ mutations as reported in the Ariel 3 Trial (100).

Novel therapeutic approaches for the treatment of ovarian cancer. Besides these conventional therapies, novel approaches for the treatment of advanced or metastatic ovarian cancer are being developed and studied. Modest results have been obtained in several clinical trials assessing the efficacy of immune checkpoint inhibitors (ICIs) already used for the treatment of several advanced and metastatic tumors (110-112). In particular, the administration of anti-PD-1 (nivolumab or pembrolizumab) or anti-PD-L1 (atezolizumab) in advanced ovarian cancer has a good response only in $10-15 \%$ of patients (113-115). Similar results have been obtained with the single administration of the anti-CTLA-4 ICI ipilimumab, which is effective only in a small fraction of patients who has previously received an anticancer therapeutic vaccine (116). Overall, single-agent ICI administration shows limited efficacy in advanced ovarian cancer, therefore novel protocols assessing the concomitant administration of ipilimumab and nivolumab have been proposed (117). Such studies have demonstrated an improved and longer response rate in patients treated with two ICIs compared with patients treated with nivolumab alone, thus replacing the single-agent ICI regimens (117). A recent review of the literature collected all the completed and ongoing clinical trials using different combinations of ICIs, selective inhibitors or chemotherapeutic agents showing encouraging and conflicting results based on the clinical and molecular features of the patients enrolled (118) (Fig. 1).

Other investigated therapeutic options for advanced ovarian cancers are represented by therapeutic vaccines, adoptive cellular therapy, $\mathrm{T}$ cell transfer and chimeric antigen receptor $\mathrm{T}$-cell therapy; however, further clinical studies are needed to assess the efficacy and safety of these further treatments (119).

Finally, several treatments are available as maintenance or palliative therapy for disseminated and metastatic ovarian cancer. Similarly, VEGFR inhibitors, including pazopanib, nintedanib and cediranib, are often used for the treatment of recurrent platinum-resistant ovarian cancer (100). In line with these treatments, VEGF inhibitors such as aflibercept are used in case of malignant ascites showing an improvement of time to next paracentesis but not of OS (120). 


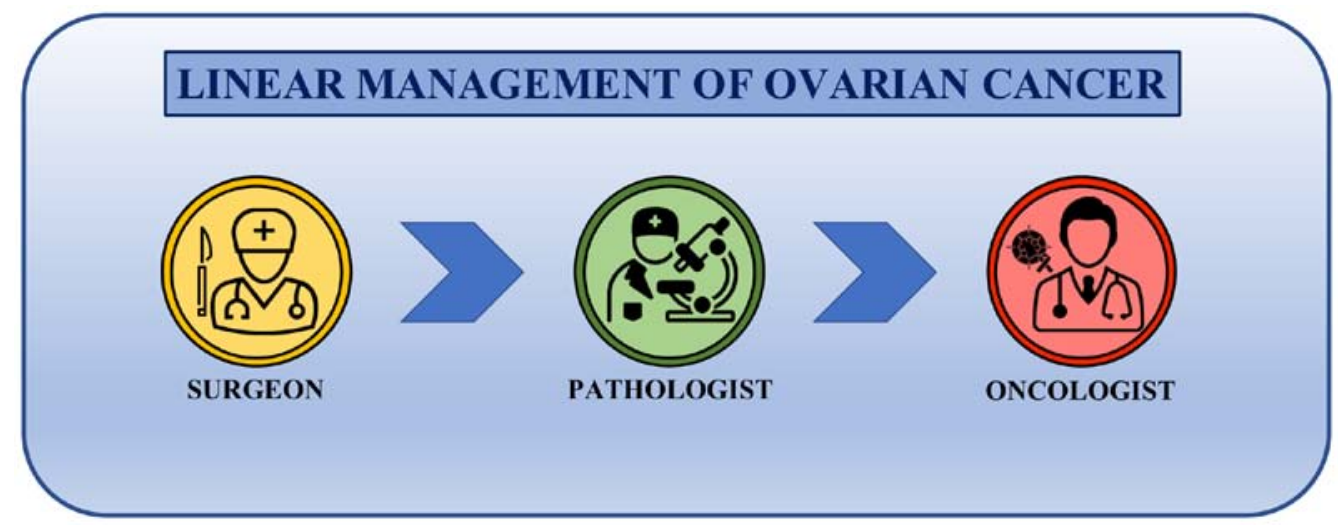

Figure 2. Linear management of ovarian cancer. Main players of ovarian cancer management are the surgeon who removes the tumor, the pathologist who assesses the tumor histotype and the medical oncologist who selects and starts the pharmacological treatments. There is no interaction between these three main specialists in the management of the patient with ovarian cancer.

Despite the availability of all these surgical and pharmacological treatments, the prognosis of patients with ovarian cancer is often poor. To improve the quality of life and life expectancy of these patients, it is necessary to opt for therapeutic choices that take into account the patient's comorbidities, the adverse effects of therapies and the patient's age. Therefore, the management of the patient with ovarian cancer is extremely complex and requires the convergence of different professional skills to ensure high standards of care.

5th ovarian cancer consensus conference of Tokyo. The 5th ovarian cancer consensus conferences held in Tokyo, Japan, in 2015 (121), established that platinum-based regimens are doubtless the standard of care in the first-line treatment of ovarian cancer. However, for the first time, besides highlighting the importance of the platinum-free interval (PFI) as a stratification factor or to define patient eligibility for clinical trials, great importance was given to treatment-free interval useful to improve selection of successive chemotherapy regimens for patients with recurrent disease.

The main decision criterion for second-line treatments is the definition of platinum-sensitivity or resistance. Sensitivity to platinum-based treatments must be assessed after a period of at least 6 months; however, there is a linear relationship between PFI and platinum sensitivity, therefore the evaluation of PFI is of primary importance in future therapeutic choices and must be considered as a continuous variable in the decision-making process leading to the new therapy. Furthermore, PFI will be used as a parameter for the eligibility of patients in novel clinical trials, therefore the evaluation of PFI cannot be limited to a fixed 6-month window but should be evaluated periodically.

Overall, platinum-based therapy remains the most effective therapy in the management of epithelial ovarian cancer, and primary PFI provides relevant prognostic and predictive information. A significant fraction of patients receives different lines of platinum-based therapy, thus evaluating the interval of time after the most recent line can provide prognostic information about acquired resistance and clonal evolution of the tumor due to intervening non-platinum treatments. Over the years different non-platinum agents have been integrated into conventional therapy; this led to the need of new prognostic and predictive markers to make the best treatment decisions for the management of recurrence (121).

\section{Ovarian cancer management: From linear to multidisciplinary patient-centered care approach}

As aforementioned, the symptomatology, diagnosis, staging and treatments of ovarian cancer are extremely complex and require the convergence of various specialists able to provide the gynecological oncologist with a clinical picture as detailed as possible, useful for designing the appropriate therapeutic protocol for each patient. Therefore, at present, the approach to the patient with advanced ovarian cancer should be multidisciplinary. This includes a team of experts who follow the patient step by step during the diagnosis, surgical therapy, pharmacological therapy, rehabilitation and follow-up, creating a collaborative network where the patient is at the center and can benefit of high standards of care in the perspective of personalized medicine and patient-centered care (122).

In this context, over the decades, great advancements in the management of patients with ovarian cancer have occurred, passing from a linear approach to care, where the patient is treated by individual specialists without communication between them, to a multidisciplinary and integrated approach where different specialists share clinical information and chose the best therapeutic options together $(123,124)$.

Until 30 years ago, the therapeutic approach followed a linear trend where the main stakeholders of cancer management were the surgeon, who operated the surgical resection of the tumor, the pathologist, who made the histological diagnosis, and the medical oncologist, who dealt with the therapeutic schedule to be administered (Fig. 2). Although other professionals participated in the clinical management of ovarian cancer (including gynecologists, radiologists and laboratory technicians), they did not actively take part in the clinical-therapeutic decisions. In addition, the interactions between the patient, the surgeon, the pathologist and the oncologist rarely occurred and each of these three professional figures made therapeutic choices without first discussing with colleagues $(125,126)$.

Since the late $80 \mathrm{~s}$, some studies have highlighted the benefits of the multidisciplinary management of patients with 
cancer in terms of diagnosis, therapeutic response, survival and quality of life, suggesting that an integrated approach to cancer could lead to improved outcomes for patients (127-129). With regards ovarian cancer, it was demonstrated that a collegial discussion can lead all the specialists to evaluate the diagnostic-therapeutic areas beyond those of their own competence, leading to an increase of awareness in the number of potential treatments available and expected pitfalls thus improving the effectiveness of treatments $(130,131)$.

The development of multidisciplinary teams has changed the previous linear approach to patients into a circular one. Indeed, the main players of ovarian cancer management are now working together, comparing their clinical findings each other in a patient-centered care approach where the patients are in the middle of a circular decision-making pathway receiving information and therapeutic options shared between the gynecological surgeon, the pathologist and the medical oncologist (Fig. 3). This circular approach to ovarian cancer treatment has introduced different therapeutic opportunities that are continuously evaluated and re-elaborated according to the clinical information received from the different specialists involved in the collaborative care network. Therefore, this approach results in a improved management of ovarian cancer and patient awareness about the status of the disease, as well as greater confidence in the therapeutic options that they will undergo (132).

Although patient-centered care has significantly improved the standard of ovarian cancer care, several studies have demonstrated that patients treated in specialized structures where multidisciplinary teams operate have an improved prognosis compared with patients treated in non-specialized centers (133-135). A possible explanation of this trend could be related to the well-organized approach to treatment in specialized hospitals with a high volume of patients with ovarian cancer per year where the components of the multidisciplinary team meet together weekly to discuss the periodic clinical, laboratory and instrumental findings useful to take appropriated and shared clinical decision. Of note, despite the undoubted advantages of a multidisciplinary team in terms of the quality of the assistance provided, this type of interdisciplinary display requires appropriate organization, time for periodic meetings, willingness to collaborate and adequate IT support; it is useful to share medical records and clinical data, favoring a continuous constructive debate for the better management of each patient (136).

As shown in Fig. 3, the gynecologist (or gynecological surgeon), the pathologist and the oncologist are the key nodes of this circular multidisciplinary network. However, as aforementioned, due to the current complexity of ovarian cancer diagnosis, staging and treatments other professionals, including the general surgeon, urologist, vascular surgeon, radiologist, nuclear medicine physicians, geneticist, molecular biologist and psycho-oncologist are fundamental in the circular patient-centered model (Fig. 4).

Only a structured center can offer well-structured multidisciplinary teams able to address all of the patient needs. In this context, the Mercado et al (137) study shows that patients treated in referral centers and treated by expert physicians have a $40 \%$ higher survival compared with patients treated in a peripheral center.
As surgery represents the gold standard for the treatment of ovarian cancer, it is well established that patients treated in experienced centers benefit from maximum cytoreductive surgical resection which positively correlates with the overall survival of patients $(135,138)$. Besides the importance of surgery, the discussion of clinical cases in the multidisciplinary team does not end with the diagnosis and surgical resection of tumor masses, but it takes place at every decision-making point, especially in case of recurrent diseases (139). In these cases, the interaction of the various specialists can lead to the design of novel and effective therapeutic strategies tailored to each patient (139). Thus, such strategies may involve new surgical interventions in the peritoneal cavity or other body districts, which requires the expertise of different types of surgeons, including urologists, vascular surgeons and general surgeons, or could lead to novel anticancer treatments using both chemo- and radiation therapies when distant metastases are observed $(140,141)$.

It is important to note that each specialist within the multidisciplinary team has a fundamental role in the diagnostic or therapeutic process. Indeed, the use of imaging techniques performed by the radiologist is fundamental to formulate a diagnosis of suspected ovarian cancer and to establish the localization of lesions $(142,143)$. In the same manner, the precise histological and biomolecular evaluation of ovarian cancer is now essential for modern cancer treatments $(144,145)$. In this context, the pathologist, geneticist and molecular biologist are fundamental for the assessment of grading, histotyping and molecular typing of ovarian cancer $(146,147)$. In addition, the multidisciplinary network of specialists is further enriched by the inclusion of breast specialists and nutritionists. In particular, breast specialists intervene in the case of BRCA1and BRCA2-positive ovarian cancer who could develop a secondary neoplasm affecting the breast $(148,149)$; while nutritionists are now a key professional figure in medical oncology departments. In fact, several studies have demonstrated that nutrition represents an important protective factor against the development of tumors (150) but also represents an effective therapeutic intervention for patients with cancer $(151,152)$. In this context, several studies have demonstrated that dietary and lifestyle interventions during cancer treatments can ameliorate the adherence to treatment as well as patient quality of life and prognosis [hazard ratio (HR) for physical activity, 0.60; 95\% CI, 0.39-0.92; $\mathrm{P}=0.02$; HR for highest vs. lowest tertile of quality diet, $0.73 ; 95 \% \mathrm{CI}, 0.55$ to $0.97 ; \mathrm{P}=0.03$ ] $(153-156)$. These data, together with the clinical features of patients allow clinicians to determine the best therapeutic approach as well as to predict the prognosis and outcomes of patients (157).

The importance of a multidisciplinary team for the management of ovarian cancer has emerged during the COVID-19 pandemic where patients with ovarian cancer have experienced difficulties in accessing medical treatment (158). Indeed, due to the spread of infection, patients with cancer have experienced delays in treatment or missed some therapies with a negative impact on the treatment response (159). In addition, patients with cancer are considered vulnerable individuals with an increased risk of COVID-19 infection and severe symptomatology (160). In this context, the multidisciplinary team involved in the management of ovarian cancer has improved novel telemedicine strategies useful to monitor 


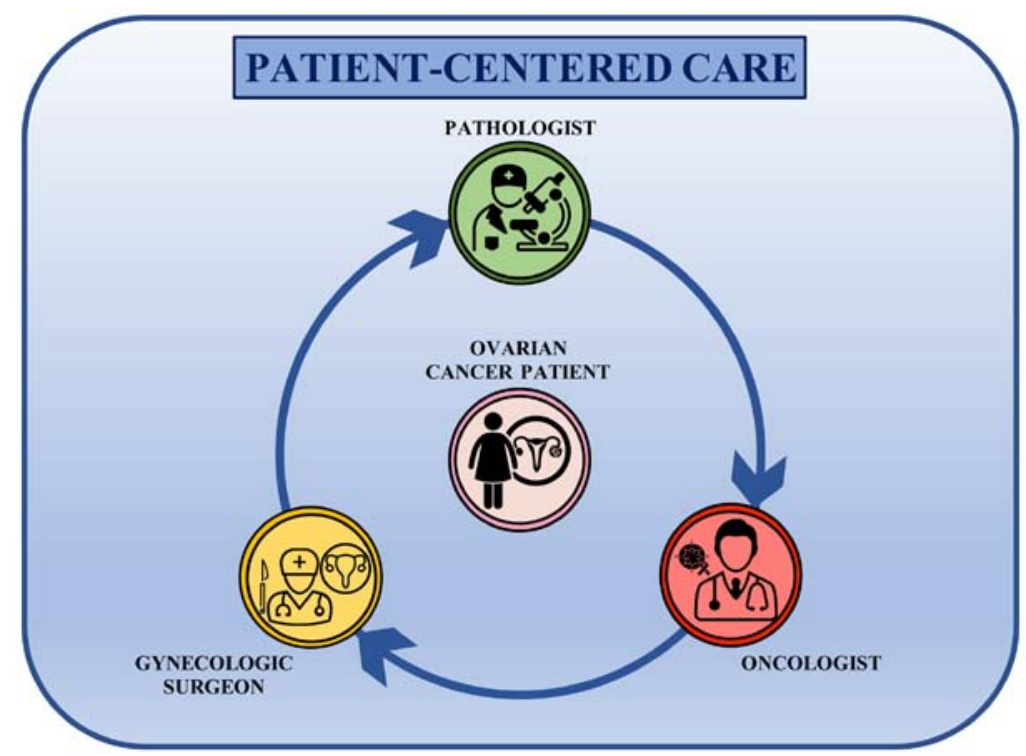

Figure 3. Circular approach to the management of patients with ovarian cancer patients. Main specialists involved in ovarian cancer care interact with each other sharing all of the relevant information and all clinical decisions are patient-centered.

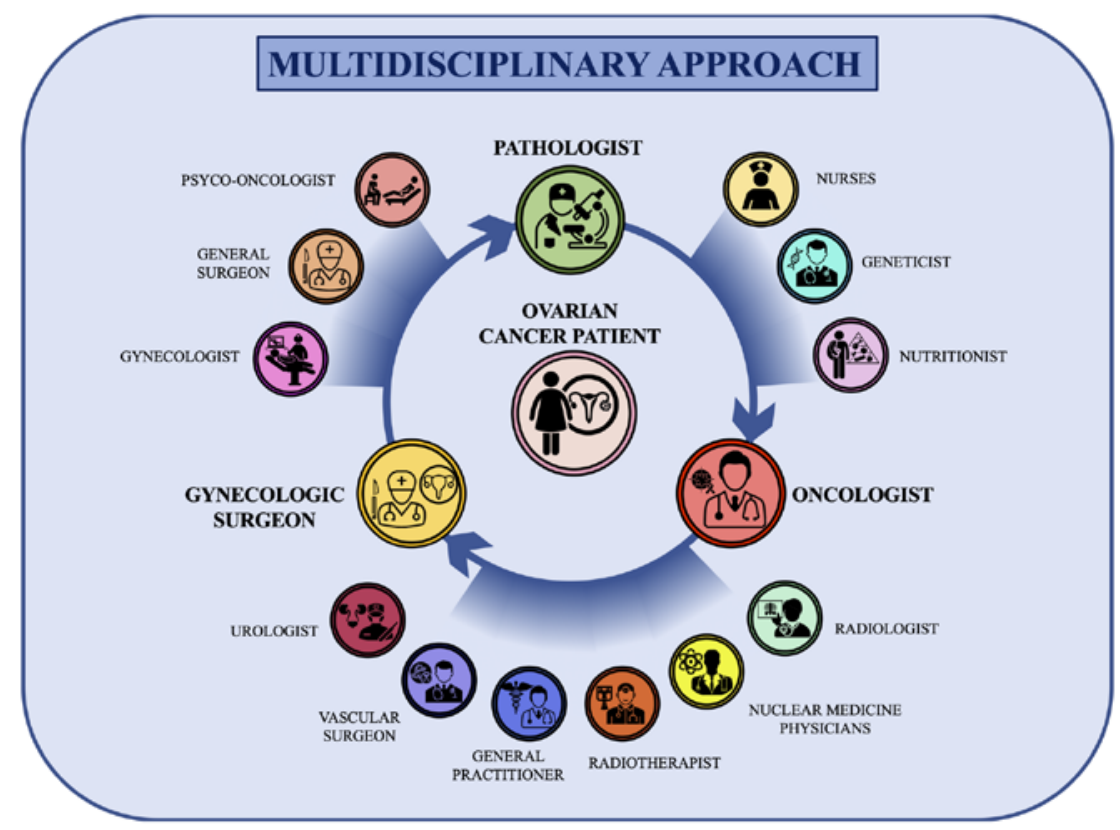

Figure 4. Circular and multidisciplinary network for the management of patients with ovarian cancer. The gynecological surgeon, pathologist and oncologist are the key nodes of the patient-centered circular multidisciplinary network. Other specialists, including nurses, geneticists, nutritionists, radiologists, nuclear medicine physicians, radiotherapists, general practitioners, vascular surgeons, urologists, gynecologists, general surgeons and psycho-oncologists, actively participate in all the decision-making steps of ovarian cancer management.

patients with ovarian cancer at a distance, thus following the progression of the disease and patient health status during the treatment. In addition, thanks to the patient-centered circular multidisciplinary network the information is easily transferred among specialists, thus increasing the speed of the implementation of therapeutic strategies and follow-up visits (161-163).

\section{Conclusions}

In recent years, the management of ovarian cancer has been significantly improved through the introduction of novel pharmacological treatments and mini-invasive surgical techniques. Besides these advancements, a multidisciplinary approach for the treatment of ovarian cancer has significantly improved the quality of life and prognosis of patients. Overall, a multidisciplinary team is able to face clinical, molecular, pathological and psychological issues of patients with ovarian cancer, ensuring a high standard of care supporting the process of personalized medicine. The importance of a multidisciplinary team and periodic meetings lays also on the constant improvement of molecular, biological and therapeutic knowledge in the field of ovarian cancer care. Indeed, the active discussion performed within a multidisciplinary 
team improves the adoption of the best therapies for patients as well as the efficacy of treatments.

\section{Acknowledgements}

Not applicable.

\section{Funding}

No funding was received.

\section{Availability of data and materials}

Not applicable.

\section{Authors' contributions}

LF, GSca and PS conceived the manuscript, performed bibliographic research and wrote the article. VL, GG and AL performed the bibliographic research and prepared the table and figures. GSci and ABD provided critical revisions. All authors provided critical revisions and read and approved the final manuscript. Data authentication is not applicable.

\section{Ethics approval and consent to participate}

Not applicable.

\section{Patient consent for publication}

Not applicable.

\section{Competing interests}

The authors declare that they have no competing interests.

\section{References}

1. Bray F, Ferlay J, Soerjomataram I, Siegel RL, Torre LA and Jemal A: Global cancer statistics 2018: GLOBOCAN estimates of incidence and mortality worldwide for 36 cancers in 185 countries. CA Cancer J Clin 68: 394-424, 2018.

2. Falzone L, Salomone S and Libra M: Evolution of cancer pharmacological treatments at the turn of the third millennium. Front Pharmacol 9: 1300, 2018

3. Torre LA, Trabert B, DeSantis CE, Miller KD, Samimi G, Runowicz CD, Gaudet MM, Jemal A and Siegel RL: Ovarian cancer statistics, 2018. CA Cancer J Clin 68: 284-296, 2018.

4. Reid BM, Permuth JB and Sellers TA: Epidemiology of ovarian cancer: A review. Cancer Biol Med 14: 9-32, 2017.

5. Shafrir AL, Rice MS, Gupta M, Terry KL, Rosner BA, Tamimi RM, Hecht JL and Tworoger SS: The association between reproductive and hormonal factors and ovarian cancer by estrogen- $\alpha$ and progesterone receptor status. Gynecol Oncol 143: 628-635, 2016.

6. D'Alonzo M, Bounous VE, Villa M and Biglia N: Current evidence of the oncological benefit-risk profile of hormone replacement therapy. Medicina (Kaunas) 55: 573, 2019.

7. Craig ER, Londoño AI, Norian LA and Arend RC: Metabolic risk factors and mechanisms of disease in epithelial ovarian cancer: A review. Gynecol Oncol 143: 674-683, 2016.

8. Fenga C, Gangemi S, Di Salvatore V, Falzone L and Libra M: Immunological effects of occupational exposure to lead (Review). Mol Med Rep 15: 3355-3360, 2017.

9. Falzone L, Marconi A, Loreto C, Franco S, Spandidos DA and Libra M: Occupational exposure to carcinogens: Benzene, pesticides and fibers (Review). Mol Med Rep 14: 4467-4474, 2016.
10. Amir S, Shah STA, Mamoulakis C, Docea AO, Kalantzi OI, Zachariou A, Calina D, Carvalho F, Sofikitis N, Makrigiannakis A and Tsatsakis A: Endocrine disruptors acting on estrogen and androgen pathways cause reproductive disorders through multiple mechanisms: A review. Int J Environ Res Public Health 18: 1464, 2021.

11. Ianoşi S, Ianoşi G, Neagoe D, Ionescu O, Zlatian O, Docea AO, Badiu C, Sifaki M, Tsoukalas D, Tsatsakis AM, et al: Age-dependent endocrine disorders involved in the pathogenesis of refractory acne in women. Mol Med Rep 14: 5501-5506, 2016.

12. Del Pup L, Mantovani A, Cavaliere C, Facchini G, Luce A, Sperlongano P, Caraglia M and Berretta M: Carcinogenetic mechanisms of endocrine disruptors in female cancers (Review). Oncol Rep 36: 603-612, 2016.

13. Rachon D: Endocrine disrupting chemicals (EDCs) and female cancer: Informing the patients. Rev Endocr Metab Disord 16: 359-364, 2015.

14. Shulman LP and Dungan JS: Cancer genetics: Risks and mechanisms of cancer in women with inherited susceptibility to epithelial ovarian cancer. Cancer Treat Res 156: 69-85, 2010.

15. Gomes R, Spinola PD, Brant AC, Matta BP, Nascimento CM, de Aquino Paes SM, Bonvicino CR, Dos Santos AC and Moreira MA: Prevalence of germline variants in consensus moderate-to-high-risk predisposition genes to hereditary breast and ovarian cancer in BRCA1/2-negative Brazilian patients. Breast Cancer Res Treat 185: 851-861, 2021.

16. Hodgson A and Turashvili G: Pathology of hereditary breast and ovarian cancer. Front Oncol 10: 531790, 2020.

17. Jara L, Morales S, de Mayo T, Gonzalez-Hormazabal P, Carrasco V and Godoy R: Mutations in BRCA1, BRCA2 and other breast and ovarian cancer susceptibility genes in Central and South American populations. Biol Res 50: 35, 2017.

18. Tedaldi G, Tebaldi M, Zampiga V, Danesi R, Arcangeli V, Ravegnani M, Cangini I, Pirini F, Petracci E, Rocca A, et al: Multiple-gene panel analysis in a case series of 255 women with hereditary breast and ovarian cancer. Oncotarget 8: 47064-47075, 2017.

19. Hanley GE, McAlpine JN, Miller D, Huntsman D, Schrader KA, Blake Gilks C and Mitchell G: A population-based analysis of germline BRCA1 and BRCA2 testing among ovarian cancer patients in an era of histotype-specific approaches to ovarian cancer prevention. BMC Cancer 18: 254, 2018.

20. Madariaga A, Lheureux S and Oza AM: Tailoring ovarian cancer treatment: Implications of BRCA1/2 mutations. Cancers (Basel) 11: 416, 2019.

21. Ashour M and Ezzat Shafik H: Frequency of germline mutations in BRCA1 and BRCA2 in ovarian cancer patients and their effect on treatment outcome. Cancer Manag Res 11: 6275-6284, 2019.

22. Tsaousis GN, Papadopoulou E, Apessos A, Agiannitopoulos K, Pepe G, Kampouri S, Diamantopoulos N, Floros T, Iosifidou R, Katopodi $\mathrm{O}$, et al: Analysis of hereditary cancer syndromes by using a panel of genes: Novel and multiple pathogenic mutations. BMC Cancer 19: 535, 2019.

23. Nakonechny QB and Gilks CB: Ovarian cancer in hereditary cancer susceptibility syndromes. Surg Pathol Clin 9: 189-199, 2016.

24. Nishioka Y, Kobayashi K, Sagae S, Sugimura M, Ishioka S, Nagata M, Terasawa K, Tokino T and Kudo R: Mutational analysis of STK11 gene in ovarian carcinomas. Jpn J Cancer Res 90: 629-632, 1999.

25. McLemore MR, Miaskowski C, Aouizerat BE, Chen LM and Dodd MJ: Epidemiological and genetic factors associated with ovarian cancer. Cancer Nurs 32: 281-288, 2009.

26. Faber MT, Kjær SK, Dehlendorff C, Chang-Claude J, Andersen KK, Høgdall E, Webb PM, Jordan SJ; Australian Cancer Study (Ovarian Cancer); Australian Ovarian Cancer Study Group, et al: Cigarette smoking and risk of ovarian cancer: A pooled analysis of 21 case-control studies. Cancer Causes Control 24: 989-1004, 2013.

27. Modugno F, Ness RB and Cottreau CM: Cigarette smoking and the risk of mucinous and nonmucinous epithelial ovarian cancer. Epidemiology 13: 467-471, 2002.

28. O'Brien KM, Tworoger SS, Harris HR, Anderson GL, Weinberg CR, Trabert B, Kaunitz AM, D'Aloisio AA, Sandler DP and Wentzensen N: Association of powder use in the genital area with risk of ovarian cancer. JAMA 323: 49-59, 2020.

29. Fletcher NM, Harper AK, Memaj I, Fan R, Morris RT and Saed GM: Molecular basis supporting the association of talcum powder use with increased risk of ovarian cancer. Reprod Sci 26: 1603-1612, 2019. 
30. Berge W, Mundt K, Luu H and Boffetta P: Genital use of talc and risk of ovarian cancer: A meta-analysis. Eur J Cancer Prev 27: 248-257, 2018.

31. Troisi R, Bjørge T, Gissler M, Grotmol T, Kitahara CM, Myrtveit Saether SM, Ording AG, Sköld C, Sørensen HT, Trabert B and Glimelius I: The role of pregnancy, perinatal factors and hormones in maternal cancer risk: A review of the evidence. J Intern Med 283: 430-445, 2018.

32. Havrilesky LJ, Moorman PG, Lowery WJ, Gierisch JM, Coeytaux RR, Urrutia RP, Dinan M, McBroom AJ, Hasselblad V, Sanders GD and Myers ER: Oral contraceptive pills as primary prevention for ovarian cancer: A systematic review and meta-analysis. Obstet Gynecol 122: 139-147, 2013.

33. Huang Z, Gao Y, Wen W, Li H, Zheng W, Shu XO and Beeghly-Fadiel A: Contraceptive methods and ovarian cancer risk among Chinese women: A report from the shanghai women's health study. Int J Cancer 137: 607-614, 2015.

34. Goff B: Symptoms associated with ovarian cancer. Clin Obstet Gynecol 55: 36-42, 2012.

35. Bankhead CR, Kehoe ST and Austoker J: Symptoms associated with diagnosis of ovarian cancer: A systematic review. BJOG 112: 857-865, 2005.

36. Rossing MA, Wicklund KG, Cushing-Haugen KL and Weiss NS: Predictive value of symptoms for early detection of ovarian cancer. J Natl Cancer Inst 102: 222-229, 2010.

37. Kehoe S: FIGO staging in ovarian carcinoma and histological subtypes. J Gynecol Oncol 31: e70, 2020.

38. Tokunaga $\mathrm{H}$, Shimada $\mathrm{M}$, Ishikawa $\mathrm{M}$ and Yaegashi N: TNM classification of gynaecological malignant tumours, eighth edition: Changes between the seventh and eighth editions. Jpn J Clin Oncol 49: 311-320, 2019.

39. Chua KJC, Patel RD, Trivedi R, Greenberg P, Beiter K, Magliaro T, Patel U and Varughese J: Accuracy in referrals to gynecologic oncologists based on clinical presentation for ovarian mass. Diagnostics (Basel) 10: 106, 2020.

40. Barnes D, Rivera R, Gibson S, Craig C, Cragun J, Monk B and Chase D: The utility of patient reported data in a gynecologic oncology clinic. Gynecol Oncol Res Pract 5: 4, 2018.

41. Funston G, Van Melle M, Baun ML, Jensen H, Helsper C, Emery J, Crosbie EJ, Thompson M, Hamilton W and Walter FM: Variation in the initial assessment and investigation for ovarian cancer in symptomatic women: A systematic review of international guidelines. BMC Cancer 19: 1028, 2019

42. Liu JH and Zanotti KM: Management of the adnexal mass Obstet Gynecol 117: 1413-1428, 2011.

43. Chan KK, Tam KF, Tse KY and Ngan HY: The role of regular physical examination in the detection of ovarian cancer recurrence. Gynecol Oncol 110: 158-161, 2008.

44. Scholler N and Urban N: CA125 in ovarian cancer. Biomark Med 1: 513-523, 2007.

45. Dochez V, Caillon H, Vaucel E, Dimet J, Winer N and Ducarme G: Biomarkers and algorithms for diagnosis of ovarian cancer: CA125, HE4, RMI and ROMA, a review. J Ovarian Res 12: 28, 2019.

46. Andersen MR, Goff BA, Lowe KA, Scholler N, Bergan L, Drescher CW, Paley P and Urban N: Use of a symptom index, CA125, and HE4 to predict ovarian cancer. Gynecol Oncol 116 : 378-383, 2010

47. Bastani A, Asghary A, Heidari MH and Karimi-Busheri F Evaluation of the sensitivity and specificity of serum level of prostasin, CA125, LDH, AFP, and hCG $+\beta$ in epithelial ovarian cancer patients. Eur J Gynaecol Oncol 38: 418-424, 2017.

48. Fischerova D and Burgetova A: Imaging techniques for the evaluation of ovarian cancer. Best Pract Res Clin Obstet Gynaecol 28 697-720, 2014

49. van Nagell JR Jr and Hoff JT: Transvaginal ultrasonography in ovarian cancer screening: Current perspectives. Int J Womens Health 6: 25-33, 2013.

50. Zhang X, Meng X, Dou T and Sun H: Diagnostic accuracy of transvaginal ultrasound examination for assigning a specific diagnosis to adnexal masses: A meta-analysis. Exp Ther Med 20 $265,2020$.

51. Meng XF, Zhu SC, Sun SJ, Guo JC and Wang X: Diffusion weighted imaging for the differential diagnosis of benign vs. malignant ovarian neoplasms. Oncol Lett 11: 3795-3802, 2016.

52. Qiao JJ, Yu J, Yu Z, Li N, Song C and Li M: Contrast-enhanced ultrasonography in differential diagnosis of benign and malignant ovarian tumors. PLoS One 10: e0118872, 2015.

53. Sahdev A: CT in ovarian cancer staging: How to review and report with emphasis on abdominal and pelvic disease for surgical planning. Cancer Imaging 16: 19, 2016.
54. Thabet A, Somarouthu B, Oliva E, Gervais DA, Hahn PF and Lee SI: Image-guided ovarian mass biopsy: Efficacy and safety. J Vasc Interv Radiol 25: 1922-1927.e1, 2014.

55. Khiewvan B, Torigian DA, Emamzadehfard S, Paydary K, Salavati A, Houshmand S, Werner TJ and Alavi A: An update on the role of PET/CT and PET/MRI in ovarian cancer. Eur J Nucl Med Mol Imaging 44: 1079-1091, 2017.

56. Zhao C, Li S, Zhao M, Zhu H and Zhu X: Prognostic values of DNA mismatch repair genes in ovarian cancer patients treated with platinum-based chemotherapy. Arch Gynecol Obstet 297: 153-159, 2018.

57. Hirotsu Y, Nakagomi H, Sakamoto I, Amemiya K, Oyama T, Mochizuki $\mathrm{H}$ and Omata M: Multigene panel analysis identified germline mutations of DNA repair genes in breast and ovarian cancer. Mol Genet Genomic Med 3: 459-466, 2015.

58. Missaoui N, Salhi S, Bdioui A, Mestiri S, Abdessayed N, Mokni M and Yacoubi MT: Immunohistochemical characterization improves the reproducibility of the histological diagnosis of ovarian carcinoma. Asian Pac J Cancer Prev 19: 2545-2551, 2018

59. Zlatian OM, Comănescu MV, Roşu AF, Roşu L, Cruce M, Găman AE, Călina CD and Sfredel V: Histochemical and immunohistochemical evidence of tumor heterogeneity in colorectal cancer. Rom J Morphol Embryol 56: 175-181, 2015.

60. Docea AO, Mitruţ P, Grigore D, Pirici D, Călina DC and Gofiţă E: Immunohistochemical expression of TGF beta (TGF- $\beta$ ), TGF beta receptor 1 (TGFBR1), and Ki67 in intestinal variant of gastric adenocarcinomas. Rom J Morphol Embryol 53 (Suppl 3): S683-S692, 2012.

61. Lee JY, Kim S, Kim YT, Lim MC, Lee B, Jung KW, Kim JW, Park SY and Won YJ: Changes in ovarian cancer survival during the 20 years before the era of targeted therapy. BMC Cancer 18 : 601,2018

62. Wu J, Sun H, Yang L, Deng Y, Yan Y, Wang S, Yang G and Ma H: Improved survival in ovarian cancer, with widening survival gaps of races and socioeconomic status: A period analysis, 1983-2012. J Cancer 9: 3548-3556, 2018

63. Timmermans M, Sonke GS, Van de Vijver KK, van der Aa MA and Kruitwagen RF: No improvement in long-term survival for epithelial ovarian cancer patients: A population-based study between 1989 and 2014 in the Netherlands. Eur J Cancer 88: 31-37, 2018

64. Nagle CM, Francis JE, Nelson AE, Zorbas H, Luxford K, de Fazio A, Fereday S, Bowtell DD, Green AC and Webb PM: Reducing time to diagnosis does not improve outcomes for women with symptomatic ovarian cancer: A report from the Australian ovarian cancer study group. J Clin Oncol 29: 2253-2258, 2011.

65. Engel J,Eckel R, Schubert-Fritschle G, Kerr J, Kuhn W, Diebold J, Kimmig R, Rehbock J and Hölzel D: Moderate progress for ovarian cancer in the last 20 years: Prolongation of survival, but no improvement in the cure rate. Eur J Cancer 38: 2435-2445, 2002.

66. Martín-Cameán M, Delgado-Sánchez E, Piñera A, Diestro MD, De Santiago J and Zapardiel I: The role of surgery in advanced epithelial ovarian cancer. Ecancermedicalscience 10: 666, 2016.

67. Vinotha T, Anitha T, Ajit S, Rachel C and Abraham P: The role of completion surgery in ovarian cancer. J Obstet Gynaecol India 66 (Suppl 1): S435-S440, 2016.

68. Fagotti A, Perelli F, Pedone L and Scambia G: Current recommendations for minimally invasive surgical staging in ovarian cancer. Curr Treat Options Oncol 17: 3, 2016.

69. Hall M, Savvatis K, Nixon K, Kyrgiou M, Hariharan K, Padwick M, Owens O, Cunnea P, Campbell J, Farthing A, et al: Maximal-effort cytoreductive surgery for ovarian cancer patients with a high tumor burden: Variations in practice and impact on outcome. Ann Surg Oncol 26: 2943-2951,2019.

70. Shih KK and Chi DS: Maximal cytoreductive effort in epithelial ovarian cancer surgery. J Gynecol Oncol 21: 75-80, 2010.

71. Suh DH, Chang SJ, Song T, Lee S, Kang WD, Lee SJ, Roh JW, Joo WD, Yoon JH, Jeong DH, et al: Practice guidelines for management of ovarian cancer in Korea: A Korean society of gynecologic oncology consensus statement. J Gynecol Oncol 29: e56, 2018.

72. Kim SR, Kotsopoulos J, Sun P, Bernardini M, Laframboise S, Ferguson S, Rosen B, Narod SA and May T: The impacts of neoadjuvant chemotherapy and of cytoreductive surgery on ten-year survival from advanced ovarian cancer. Int J Gynaecol Obstet 2017 (Epub ahead of print).

73. Choi N, Chang JH, Kim S and Kim HJ: Radiation for persistent or recurrent epithelial ovarian cancer: A need for reassessment. Radiat Oncol J 35: 144-152, 2017. 
74. Dowdy SC, Metzinger DS, Gebhart JB, Srivatsa P, Haddock MG, Suman VJ and Podratz KC: Salvage whole-abdominal radiation therapy after second-look laparotomy or secondary debulking surgery in patients with ovarian cancer. Gynecol Oncol 96: 389-394, 2005

75. Shimada T, Saito T, Shimokawa M, Shimamoto K, Matsushita S, Yamaguchi S, Ariyoshi K and Okadome M: Improvement in the prognosis of ovarian cancer in the era before addition of molecular targeting therapy. Jpn J Clin Oncol 47: 494-498, 2017.

76. Ledermann JA: First-line treatment of ovarian cancer: Questions and controversies to address. Ther Adv Med Oncol 10: $1758835918768232,2018$.

77. Sato S and Itamochi H: Neoadjuvant chemotherapy in advanced ovarian cancer: Latest results and place in therapy. Ther Adv Med Oncol 6: 293-304, 2014.

78. Chambers LM, Son J, Radeva M and DeBernardo R: Evaluation of non-completion of intraperitoneal chemotherapy in patients with advanced epithelial ovarian cancer. J Gynecol Oncol 30: e93, 2019.

79. Yoon JY, Koo YJ, Kim MJ, Kim TJ, Lim KT and Lee KH: Survival outcomes and toxicity of intraoperative intraperitoneal chemotherapy in advanced epithelial ovarian cancer. Obstet Gynecol Sci 57: 484-491, 2014

80. Chan JK, Brady MF, Penson RT, Huang H, Birrer MJ, Walker JL, DiSilvestro PA, Rubin SC, Martin LP, Davidson SA, et al: Weekly vs. Every-3-week paclitaxel and carboplatin for ovarian cancer. $\mathrm{N}$ Engl J Med 374: 738-748, 2016.

81. Pignata S, Scambia G, Katsaros D, Gallo C, Pujade-Lauraine E, De Placido S, Bologna A, Weber B, Raspagliesi F, Panici PB, et al: Carboplatin plus paclitaxel once a week versus every 3 weeks in patients with advanced ovarian cancer (MITO-7): A randomised, multicentre, open-label, phase 3 trial. Lancet Oncol 15: 396-405, 2014.

82. Katsumata N, Yasuda M, Isonishi S, Takahashi F, Michimae H, Kimura E, Aoki D, Jobo T, Kodama S, Terauchi F, et al: Long-term results of dose-dense paclitaxel and carboplatin versus conventional paclitaxel and carboplatin for treatment of advanced epithelial ovarian, fallopian tube, or primary peritoneal cancer (JGOG 3016): A randomised, controlled, open-label trial. Lancet Oncol 14: 1020-1026, 2013.

83. Marchetti C, Muzii L, Romito A and Benedetti Panici P First-line treatment of women with advanced ovarian cancer: Focus on bevacizumab. Onco Targets Ther 12: 1095-1103, 2019.

84. Komiyama S, Kato K, Inokuchi Y, Takano H, Matsumoto T, Hongo A, Asai-Sato M, Arakawa A, Kamiura S, Tabata T, et al: Bevacizumab combined with platinum-taxane chemotherapy as first-line treatment for advanced ovarian cancer: A prospective observational study of safety and efficacy in Japanese patients (JGOG3022 trial). Int J Clin Oncol 24: 103-114, 2019.

85. Perren TJ, Swart AM, Pfisterer J, Ledermann JA, PujadeLauraine E, Kristensen G, Carey MS, Beale P, Cervantes A, Kurzeder C, et al: A phase 3 trial of bevacizumab in ovarian cancer. N Engl J Med 365: 2484-2496, 2011.

86. Burger RA, Brady MF, Bookman MA, Fleming GF, Monk BJ, Huang H, Mannel RS, Homesley HD, Fowler J, Greer BE, et al: Incorporation of bevacizumab in the primary treatment of ovarian cancer. N Engl J Med 365: 2473-2483, 2011.

87. Qian X, Qin J, Pan S, Li X, Pan Y and Ma S: Maintenance therapy in ovarian cancer with targeted agents improves PFS and OS: A systematic review and meta-analysis. PLoS One 10: e0139026, 2015.

88. Hess LM, Rong N, Monahan PO, Gupta P, Thomaskutty C and Matei D: Continued chemotherapy after complete response to primary therapy among women with advanced ovarian cancer: A meta-analysis. Cancer 116: 5251-5260, 2010.

89. Baert T, Ferrero A, Sehouli J, O'Donnell DM, González-Martín A, Joly F, van der Velden J, Blecharz P, Tan DSP, Querleu D, et al: The systemic treatment of recurrent ovarian cancer revisited. Ann Oncol: Mar 3, 2021 (Epub ahead of print). doi: 10.1016/j.annonc.2021.02.015

90. Lindemann K, Gao B, Mapagu C, Fereday S, Emmanuel C, Alsop K, Traficante N; Australian Ovarian Cancer Study Group, Harnett PR, Bowtell DDL and DeFazio A: Response rates to second-line platinum-based therapy in ovarian cancer patients challenge the clinical definition of platinum resistance. Gynecol Oncol 150: 239-246, 2018.

91. Guo B, Lian W, Liu S, Cao Y and Liu J: Comparison of diagnostic values between CA125 combined with CA199 and ultrasound combined with CT in ovarian cancer. Oncol Lett 17: 5523-5528, 2019.
92. Mancari R, Cutillo G, Bruno V, Vincenzoni C, Mancini E, Baiocco E, Bruni S, Vocaturo G, Chiofalo B and Vizza E: Development of new medical treatment for epithelial ovarian cancer recurrence. Gland Surg 9: 1149-1163, 2020.

93. Kozłowska E, Vallius T, Hynninen J, Hietanen S, Färkkilä A and Hautaniemi S: Virtual clinical trials identify effective combination therapies in ovarian cancer. Sci Rep 9: 18678, 2019.

94. Burger RA, Sill MW, Monk BJ, Greer BE and Sorosky JI: Phase II trial of bevacizumab in persistent or recurrent epithelial ovarian cancer or primary peritoneal cancer: A gynecologic oncology group study. J Clin Oncol 25: 5165-5171, 2007.

95. Bamias A, Gibbs E, Khoon Lee C, Davies L, Dimopoulos M, Zagouri F, Veillard AS, Kosse J, Santaballa A, Mirza MR, et al: Bevacizumab with or after chemotherapy for platinum-resistant recurrent ovarian cancer: Exploratory analyses of the AURELIA trial. Ann Oncol 28: 1842-1848, 2017.

96. Luvero D, Milani A and Ledermann JA: Treatment options in recurrent ovarian cancer: Latest evidence and clinical potential. Ther Adv Med Oncol 6: 229-239, 2014.

97. Dockery LE, Tew WP, Ding K and Moore KN: Tolerance and toxicity of the PARP inhibitor olaparib in older women with epithelial ovarian cancer. Gynecol Oncol 147: 509-513, 2017.

98. Kaufman B, Shapira-Frommer R, Schmutzler RK, Audeh MW, Friedlander M, Balmaña J, Mitchell G, Fried G, Stemmer SM Hubert A, et al: Olaparib monotherapy in patients with advanced cancer and a germline BRCA1/2 mutation. J Clin Oncol 33: 244-250, 2015.

99. Lheureux S, Braunstein M and Oza AM: Epithelial ovarian cancer: Evolution of management in the era of precision medicine. CA Cancer J Clin 69: 280-304, 2019.

100. Cortez AJ, Tudrej P, Kujawa KA and Lisowska KM: Advances in ovarian cancer therapy. Cancer Chemother Pharmacol 81: 17-38, 2018.

101. Jiang X, Li W, Li X, Bai H and Zhang Z: Current status and future prospects of PARP inhibitor clinical trials in ovarian cancer. Cancer Manag Res 11: 4371-4390, 2019.

102. Moore K, Colombo N, Scambia G, Kim BG, Oaknin A, Friedlander M,Lisyanskaya A, Floquet A, Leary A, Sonke GS, et al: Maintenance olaparib in patients with newly diagnosed advanced ovarian cancer. N Engl J Med 379: 2495-2505, 2018.

103. Banerjee S, Gonzalez-Martin A, Harter P, Lorusso D, Moore KN, Oaknin A and Ray-Coquard I: First-line PARP inhibitors in ovarian cancer: Summary of an ESMO Open-Cancer Horizons round-table discussion. ESMO Open 5: e001110, 2020.

104. Ray-Coquard I, Pautier P,Pignata S, Pérol D, González-Martín A Berger R, Fujiwara K, Vergote I, Colombo N, Mäenpää J, et al: Olaparib plus bevacizumab as first-line maintenance in ovarian cancer. N Engl J Med 381: 2416-2428, 2019.

105. González-Martín A, Pothuri B, Vergote I, DePont Christensen R, Graybill W, Mirza MR, McCormick C, Lorusso D, Hoskins P, Freyer $\mathrm{G}$, et al: Niraparib in patients with newly diagnosed advanced ovarian cancer. N Engl J Med 381: 2391-2402, 2019.

106. Pujade-Lauraine E, Ledermann JA, Selle F, Gebski V, Penson RT, Oza AM, Korach J, Huzarski T, Poveda A, Pignata S, et al: Olaparib tablets as maintenance therapy in patients with platinum-sensitive, relapsed ovarian cancer and a BRCA1/2 mutation (SOLO2/ENGOT-Ov21): A double-blind, randomised, placebo-controlled, phase 3 trial.Lancet Oncol 18: 1274-1284, 2017.

107. Mirza MR, Monk BJ, Herrstedt J, Oza AM, Mahner S, Redondo A, Fabbro M, Ledermann JA, Lorusso D, Vergote I, et al: Niraparib maintenance therapy in platinum-sensitive, recurrent ovarian cancer. N Engl J Med 375: 2154-2164, 2016.

108. Ledermann J, Harter P, Gourley C, Friedlander M, Vergote I, Rustin G, Scott CL, Meier W, Shapira-Frommer R, Safra T, et al: Olaparib maintenance therapy in patients with platinum-sensitive relapsed serous ovarian cancer: A preplanned retrospective analysis of outcomes by BRCA status in a randomised phase 2 trial. Lancet Oncol 15: 852-861, 2014.

109. Balasubramaniam S, Beaver JA, Horton S, Fernandes LL, Tang S, Horne HN, Liu J, Liu C, Schrieber SJ, Yu J, et al: FDA approval summary: Rucaparib for the treatment of patients with deleterious BRCA mutation-associated advanced ovarian cancer. Clin Cancer Res 23: 7165-7170, 2017.

110. Leonardi GC, Candido S, Falzone L, Spandidos DA and Libra M: Cutaneous melanoma and the immunotherapy revolution (Review). Int J Oncol 57: 609-618, 2020.

111. Vivarelli S, Falzone L, Grillo CM, Scandurra G, Torino F and Libra M: Cancer management during COVID-19 pandemic: Is immune checkpoint inhibitors-based immunotherapy harmful or beneficial? Cancers (Basel) 12: 2237, 2020 
112. Christofi T, Baritaki S, Falzone L, Libra M and Zaravinos A: Current perspectives in cancer immunotherapy. Cancers (Basel) 11: 1472, 2019.

113. Liu JF, Gordon M, Veneris J, Braiteh F, Balmanoukian A, Eder JP, Oaknin A, Hamilton E, Wang Y, Sarkar I, et al: Safety, clinical activity and biomarker assessments of atezolizumab from a Phase I study in advanced/recurrent ovarian and uterine cancers. Gynecol Oncol 154: 314-322, 2019.

114. Varga A, Piha-Paul S, Ott PA, Mehnert JM, Berton-Rigaud D, Morosky A, Yang P, Ruman J and Matei D: Pembrolizumab in patients with programmed death ligand 1-positive advanced ovarian cancer: Analysis of KEYNOTE-028. Gynecol Oncol 152: 243-250, 2019.

115. Hamanishi J, Mandai M, Ikeda T, Minami M, Kawaguchi A, Murayama T, Kanai M, Mori Y, Matsumoto S, Chikuma S, et al: Safety and antitumor activity of anti-PD-1 antibody, nivolumab, in patients with platinum-resistant ovarian cancer. J Clin Oncol 33: 4015-4022, 2015.

116. Hodi FS, Butler M, Oble DA, Seiden MV, Haluska FG, Kruse A, Macrae S, Nelson M, Canning C, Lowy I, et al: Immunologic and clinical effects of antibody blockade of cytotoxic T lymphocyte-associated antigen 4 in previously vaccinated cancer patients. Proc Natl Acad Sci USA 105 : 3005-3010, 2008

117. Zamarin D, Burger RA, Sill MW, Powell DJ Jr, Lankes HA Feldman MD, Zivanovic O, Gunderson C, Ko E, Mathews C, et al: Randomized phase II trial of nivolumab versus nivolumab and ipilimumab for recurrent or persistent ovarian cancer: An NRG oncology study. J Clin Oncol 38: 1814-1823, 2020.

118. Palaia I, Tomao F, Sassu CM, Musacchio L and Benedetti Panici P: Immunotherapy for ovarian cancer: Recent advances and combination therapeutic approaches. Onco Targets Ther 13 6109-6129, 2020

119. Chandra A, Pius C, Nabeel M, Nair M, Vishwanatha JK Ahmad S and Basha R: Ovarian cancer: Current status and strategies for improving therapeutic outcomes. Cancer Med 8: 7018-7031, 2019.

120. Gotlieb WH, Amant F, Advani S, Goswami C, Hirte H, Provencher D, Somani N, Yamada SD, Tamby JF and Vergote I: Intravenous aflibercept for treatment of recurrent symptomatic malignant ascites in patients with advanced ovarian cancer: A phase 2, randomised, double-blind, placebo-controlled study. Lancet Oncol 13: 154-162, 2012.

121. McGee J, Bookman M, Harter P, Marth C, McNeish I, Moore KN, Poveda A, Hilpert F, Hasegawa K, Bacon M, et al: Fifth ovarian cancer consensus conference: Individualized therapy and patient factors. Ann Oncol 28: 702-710, 2017.

122. Aletti GD, Garbi A, Messori P, Achilarre MT, Zanagnolo V, Rizzo S, Alessi S, Bocciolone L, Landoni F, Biffi R, et al Multidisciplinary approach in the management of advanced ovarian cancer patients: A personalized approach. Results from a specialized ovarian cancer unit. Gynecol Oncol 144: 468-473, 2017.

123. Pillay B, Wootten AC, Crowe H, Corcoran N, Tran B, Bowden P, Crowe $\mathrm{J}$ and Costello AJ: The impact of multidisciplinary team meetings on patient assessment, management and outcomes in oncology settings: A systematic review of the literature. Cancer Treat Rev 42: 56-72, 2016

124. Junor EJ, Hole DJ and Gillis CR: Management of ovarian cancer: Referral to a multidisciplinary team matters. Br J Cancer 70: 363-370, 1994.

125. Gleeson M, Meiser B, Barlow-Stewart K, Trainer AH, Tucker K, Watts KJ, Friedlander M and Kasparian N: Communication and information needs of women diagnosed with ovarian cancer regarding treatment-focused genetic testing. Oncol Nurs Forum 40: 275-283, 2013.

126. Stead ML, Brown JM, Fallowfield L and Selby P: Lack of communication between healthcare professionals and women with ovarian cancer about sexual issues. Br $\mathrm{J}$ Cancer 88 : 666-671, 2003.

127. Selby P, Gillis C and Haward R: Benefits from specialised cancer care. Lancet 348: 313-318, 1996.

128. August DA, Carpenter LC, Harness JK, Delosh T, Cody RL, Adler DD, Oberman H, Wilkins E, Schottenfeld D and McNeely SG: Benefits of a multidisciplinary approach to breast care. J Surg Oncol 53: 161-167, 1993.

129. Vinciguerra V, Degnan TJ, Sciortino A, O'Connell M, Moore T, Brody R, Budman D, Eng M and Carlton D: A comparative assessment of home versus hospital comprehensive treatment for advanced cancer patients. J Clin Oncol 4: 1521-1528, 1986.
130. Heudel PE, Devouassoux-Shisheboran M, Taieb S Genestie C, Selle F, Morice P, Rouzier R and Ray-Coquard I: Multidisciplinary management of advanced ovarian cancer for an optimal therapeutic strategy. Eur J Gynaecol Oncol 38: 175-180, 2017

131. Bjørn SF, Schnack TH, Lajer H, Christensen IJ, Lundvall L, Thomsen LN and Høgdall C: Classification of ovarian cancer surgery facilitates treatment decisions in a gynecological multidisciplinary team. Int J Gynecol Cancer 27: 382-389, 2017.

132. Pozzar RA and Berry DL: Patient-centered research priorities in ovarian cancer: A systematic review of potential determinants of guideline care. Gynecol Oncol 147: 714-722, 2017.

133. Moterani VC, Tiezzi DG, de Andrade JM and Candido Dos Reis FJ: Analysis of the relationship between hospital characteristics and survival in ovarian cancer: A historical cohort. J Surg Oncol 122: 1802-1807, 2020.

134. Wright JD, Chen L, Hou JY, Burke WM, Tergas AI, Ananth CV, Neugut AI and Hershman DL: Association of hospital volume and quality of care with survival for ovarian cancer. Obstet Gynecol 130: 545-553, 2017.

135. Vernooij F, Heintz AP, Coebergh JW, Massuger LF, Witteveen PO and van der Graaf Y: Specialized and high-volume care leads to better outcomes of ovarian cancer treatment in the Netherlands. Gynecol Oncol 112: 455-461, 2009.

136. Ke KM, Blazeby JM, Strong S, Carroll FE, Ness AR and Hollingworth W: Are multidisciplinary teams in secondary care cost-effective? A systematic review of the literature. Cost Eff Resour Alloc 11: 7, 2013

137. Mercado C, Zingmond D, Karlan BY, Sekaris E, Gross J, Maggard-Gibbons M, Tomlinson JS and Ko CY: Quality of care in advanced ovarian cancer: The importance of provider specialty. Gynecol Oncol 117: 18-22, 2010.

138. Long B, Chang J, Ziogas A, Tewari KS, Anton-Culver H and Bristow RE: Impact of race, socioeconomic status, and the health care system on the treatment of advanced-stage ovarian cancer in California. Am J Obstet Gynecol 212: 468.e1-9, 2015.

139. Scott R, Hawarden A, Russell B and Edmondson RJ: Decisionmaking in gynaecological oncology multidisciplinary team meetings: A cross-sectional, observational study of ovarian cancer cases. Oncol Res Treat 43: 70-77, 2020.

140. Rausei S, Uccella S, D'Alessandro V, Gisone B, Frattini F, Lianos G, Rovera F, Boni L, Dionigi G and Ghezzi F: Aggressive surgery for advanced ovarian cancer performed by a multidisciplinary team: A retrospective analysis on a large series of patients. Surg Open Sci 1: 43-47, 2019.

141. Burton E, Chase D, Yamamoto M, de Guzman J, Imagawa D and Berman ML: Surgical management of recurrent ovarian cancer: The advantage of collaborative surgical management and a multidisciplinary approach. Gynecol Oncol 120: 29-32, 2011.

142. Forstner R, Meissnitzer M and Cunha TM: Update on imaging of ovarian cancer. Curr Radiol Rep 4: 31, 2016.

143. Guerriero S, Saba L, Alcazar JL, Pascual MA, Ajossa S, Perniciano M, Piras A, Sedda F, Peddes C, Fabbri P, et al: Past, present and future ultrasonographic techniques for analyzing ovarian masses. Womens Health (Lond) 11: 369-383, 2015.

144. Avril S: Histopathological markers of treatment response and recurrence risk in ovarian cancers and borderline tumors. Pathologe 38 (Suppl 3): S180-S191, 2017.

145. Rojas V, Hirshfield KM, Ganesan S and Rodriguez-Rodriguez L: Molecular characterization of epithelial ovarian cancer: Implications for diagnosis and treatment. Int J Mol Sci 17: 2113, 2016.

146. Ramalingam P: Morphologic, immunophenotypic, and molecular features of epithelial ovarian cancer. Oncology (Williston Park) 30: 166-176, 2016

147. Lalwani N, Prasad SR, Vikram R, Shanbhogue AK, Huettner PC and Fasih N: Histologic, molecular, and cytogenetic features of ovarian cancers: Implications for diagnosis and treatment. Radiographics 31: 625-646, 2011

148. Kim H, Choi DH, Park W, Im YH, Ahn JS, Park YH, Nam SJ, Kim SW, Lee JE, Yu JH, et al: The association between non-breast and ovary cancers and BRCA mutation in first- and second-degree relatives of high-risk breast cancer patients: A large-scale study of Koreans. Hered Cancer Clin Pract 17: 1, 2019.

149. Pruthi S, Gostout BS and Lindor NM: Identification and management of women with BRCA mutations or hereditary predisposition for breast and ovarian cancer. Mayo Clin Proc 85: $1111-1120,2010$ 
150. Di Furia L, Rusciano MR, Leonardini L, Rossi P, Giammarchi C, Vittori E, Tilocca S, Russo FL, Montuori P, Triassi M, et al: A nutritional approach to the prevention of cancer: From assessment to personalized intervention. Transl Med UniSa 13: 33-41, 2016.

151. Zheng B, Shen H, Han H, Han T and Qin Y: Dietary fiber intake and reduced risk of ovarian cancer: A meta-analysis. Nutr J 17: $99,2018$.

152. Crane TE, Khulpateea BR, Alberts DS, Basen-Engquist K and Thomson CA: Dietary intake and ovarian cancer risk: A systematic review. Cancer Epidemiol Biomarkers Prev 23: 255-273, 2014.

153. Montagnese C, Porciello G, Vitale S, Palumbo E, Crispo A Grimaldi M, Calabrese I, Pica R, Prete M,Falzone L, et al: Quality of life in women diagnosed with breast cancer after a 12-month treatment of lifestyle modifications. Nutrients 13: 136, 2020.

154. Porciello G, Montagnese C, Crispo A, Grimaldi M, Libra M, Vitale S, Palumbo E, Pica R, Calabrese I, Cubisino S, et al: Mediterranean diet and quality of life in women treated for breast cancer: A baseline analysis of DEDiCa multicentre trial. PLoS One 15: e0239803, 2020.

155. Hansen JM, Nagle CM, Ibiebele TI, Grant PT, Obermair A, Friedlander ML, DeFazio A and Webb PM; Ovarian Cancer Prognosis and Lifestyle Study Group: A healthy lifestyle and survival among women with ovarian cancer. Int J Cancer 147: 3361-3369, 2020.

156. Thomson CA, E Crane T, Wertheim BC, Neuhouser ML, Li W, Snetselaar LG, Basen-Engquist KM, Zhou Y and Irwin ML: Diet quality and survival after ovarian cancer: Results from the women's health initiative. J Natl Cancer Inst 106: dju314, 2014.

157. Peres LC, Cushing-Haugen KL, Anglesio M, Wicklund K, Bentley R, Berchuck A, Kelemen LE, Nazeran TM, Gilks CB, Harris HR, et al: Histotype classification of ovarian carcinoma: A comparison of approaches. Gynecol Oncol 151: 53-60, 2018.

158. Jacome LS, Deshmukh SK, Thulasiraman P, Holliday NP and Singh S: Impact of COVID-19 pandemic on ovarian cancer management: Adjusting to the new normal. Cancer Manag Res 13: 359-366, 2021.
159. Vivarelli S, Falzone L, Torino F, Scandurra G, Russo G, Bordonaro R, Pappalardo F, Spandidos DA, Raciti G and Libra M: Immune-checkpoint inhibitors from cancer to COVID-19: A promising avenue for the treatment of patients with COVID-19 (Review). Int J Oncol 58: 145-157, 2021.

160. Tsatsakis A, Calina D, Falzone L, Petrakis D, Mitrut R, Siokas V, Pennisi M, Lanza G, Libra M, Doukas SG, et al: SARS-CoV-2 pathophysiology and its clinical implications: An integrative overview of the pharmacotherapeutic management of COVID-19. Food Chem Toxicol 146: 111769, 2020.

161. Zimmerman BS, Seidman D, Berger N, Cascetta KP Nezolosky M, Trlica K, Ryncarz A, Keeton C, Moshier E and Tiersten A: Patient perception of telehealth services for breast and gynecologic oncology care during the COVID-19 pandemic: A single center survey-based study. J Breast Cancer 23: 542-552, 2020.

162. Mancebo G, Solé-Sedeño JM, Membrive I, Taus A, Castells M, Serrano L, Carreras R and Miralpeix E: Gynecologic cancer surveillance in the era of SARS-CoV-2 (COVID-19). Int J Gynecol Cancer 5: ijgc-2020-001942, 2020.

163. Frey MK, Ellis AE, Zeligs K, Chapman-Davis E, Thomas C, Christos PJ, Kolev V, Prasad-Hayes M, Cohen S, Holcomb K and Blank SV: Impact of the coronavirus disease 2019 pandemic on the quality of life for women with ovarian cancer. Am J Obstet Gynecol 223: 725.e1-725.e9, 2020.

This work is licensed under a Creative Commons Attribution-NonCommercial-NoDerivatives 4.0 International (CC BY-NC-ND 4.0) License. 